\title{
Language Matters
}

Andrew J. McLean ${ }^{1}$

Received: 6 February 2016 / Accepted: 23 March 2016/Published online: 2 May 2016

(C) Academic Psychiatry 2016

It happened again-

The use of "diabetic",

"Schizophrenic" and

Other "ics" and "ives" to label

The individual

Rather than the disease.

There were no patients present

While my attending preached,

Nor would they have

Likely protested

Had they been there.

He derided "the mid-levels,"

Mentioned "MDs" to refer

To all physicians,

As my osteopathic colleague

Sat quietly.

After a minute-

After years-

I spoke.

$\triangle$ Andrew J. McLean

andrew.mclean@med.und.edu

1 University of North Dakota School of Medicine and Health Sciences, Fargo, ND, USA 